\title{
Ecological Disaster Writing in Wang Hua's Novel Xuedou
}

\author{
LI Qian \\ School of Chinese Language and Literature, Lanzhou University, China \\ Received: August 15, 2021 \\ Accepted: August 31, 2021 \\ Published: January 31, 2022
}

To cite this article: LI Qian. (2021). Ecological Disaster Writing in Wang Hua's Novel Xuedou. Asia-Pacific Journal of Humanities and Social Sciences, 1(4), 040-044, DOI: 10.53789/j. 1653-0465. 2021.0104. 006

To link to this article: https://doi. org/10.53789/j. 1653-0465.2021.0104. 006

Abstract: Xuedou by Guizhou writer Wang Hua focuses on the ecological disaster behind industrialization. The work tells the tragic life of people in Qiaoxi Village after ecological destruction. Modernization is the beginning of the fable of rural misery. Environmental deterioration leads to the reproductive crisis in Qiaoxi Village. The distortion and alienation of women imply the suffering and pain of people from ecological imbalance. For these realistic dilemmas, the work provides a solution, that is, the awakening of ecological consciousness and the exploration of spiritual home.

Keywords: Xuedou; ecological disaster; reproductive crisis; ecological consciousness; the spiritual home

Notes on the contributor: LI Qian, a postgraduate student of Lanzhou University, has a strong academic interest in the theory of literature and art.

\section{王華小說《雪豆》中的生態災難書寫 \\ 李 茜}

蘭州大學文學院

摘 要: 貴州作家王華的《雪豆》關註工業化背後的生態災難。作品描述橋溪莊人遭受生態破壞後的悲惨人生。現 代化是鄉村苦難寓言的開始, 環境恶化導致橋溪莊出現生殖危機, 女性的畸變與異化隱含著生態失衡下人的苦和 痛。對於這些現實困境,作品給出了解決方式,即生態意識的覺醒與精神家園的探寻。

關鍵詞: 《雪豆》; 生態災難; 生殖危機; 生態意誡; 精神家園

\section{引言}


之凸顯。部分作家將對自然與社會的深沈憂思融入作品, 表現出明顯的生態意識, 在凸顯社會轉型時期生態 危機的同時, 反思現代化背景下人的精神困境。貴州作家王華結合中國鄉村現狀,捕捉生態環境惡化引發的 底層民眾精神危機, 在作品中整合鄉村經驗, 將生態災難與人的精神失落聯系起來。這些底層群體位於鄉村 與城市、傳統與現代的裂縫中, 在生態失衡的困境中搖搖欲墜。《雪豆》(原名《橋溪莊》) 是反映現代鄉土潰 敗與底層民眾精神困境的代表性作品, 深刻展現了中國在現代化發展過程中的隱憂, 以激發讀者的生態保護 觀念。目前, 《雪豆》的生態主題已引起論者關註。如文靜的《從〈橋溪莊〉看王華的生態文學創作》分析了 王華的對生態環境的關懷意識 ${ }^{(1)}$, 但仍有未詳盡處。本文以《雪豆》為研究對象, 從現代化導致的生態災難 出發, 分析作品中的家園危機、對女性的剝削與異化, 以及對底層民眾精神家園的破壞, 來探求造成生態災難 的社會因素。同時關注農民群體的自然家園保護與精神家園建構, 提倡生態正義, 呼籲合理地使用自然資 源, 倡導可持續發展。

\section{一、家園危機: 工業汗染下的橋溪莊}

《雪豆》以被小水泥廠汗染的橋溪河為原型, 塑造了橋溪莊及生活在橋溪莊的蕓蕓眾生。橋溪莊的村民 將家安在公路旁, 他們可以享受交通便利,包括進廠打工掙錢、改善生活等。這半截公路和水泥廠在他們眼 中是擁抱現代化、擺脫窮困、走向幸福的希望。但另一方面, 村民們又被茫茫的粉塵裹挾著前進,看不清前 路。他們在不能生育的困境中掙紮、呼號、逃離、死亡。作家透過《橋溪莊》給予當代受到生態環境侵襲的農 村底層民眾悲憫與關懷 ${ }^{2}$,引導讀者反思現代化進程中的環境問題。

現代化通常被認為是一個戰略上的模糊概念, 具體的涵義來自使用者的不同需求, 並以自滿和優越感貫 穿始終。對祖祖輩輩自給自足的農民來說, 城市生活優於農村生活, 現代化可以讓他們再也不用看天吃飯, 並照亮生活的前路。因此, 現代技術成了擺脫窮困生活的靈丹妙藥。但帶有諷刺意味的是, 這些淳樸的農民 想搭上這趟現代化快車努力建設自己的未來, 而現代化卻將他們排除在理想之外, 它通過舍棄這些社會群體 的利益, 換取自身的發展。面對遭到嚴重破壞的生存環境, 這些邊緣群體承受著來自現代化的惡果, 但環境 問題的均質化卻使這樣的痛苦被掩蓋。現代化不斷誘惑著淳樸的農民, 䖯食了他們的土地, 吞噬著一座又一 座鄉村, 橋溪莊正是一個典型案例。王華銳利地切人了被現代化榕幹利益, 又被無情抛棄的村莊, 迫切地想 找到突破現代鄉村桎梏的辦法。

橋溪莊是在投資建廠的大背景下 $\lceil$ 應運而生 $\rfloor$ 的, 但又充滿了不幸。它 $「$ 在省道上 $\rfloor^{3}$, 挨著整日轟鳴 的工廠。村民們守著一截公路、倚著一座工廠叔下根來, 形成了不足五十戶人家的小村莊。身強力壯的男女 在水泥廠打工, 連工廠到橋溪莊的陡坡都是村民賺錢的法子。可是, 橋溪莊既不下雨也不下雪, 「橋溪莊人 常常只有觀雨的份了, 大雨小雨都是別人的事, 橋溪莊人只有站在灰塵撲撲的橋溪莊觀看近在怘尺如註的大 雨的份」 ${ }^{\oplus}$ 。甚至女人們只懷氣胎不懷血胎。她們的肚子眼看著一天天大了起來, 即將生產的孩子卻不翼而 飛, 只生下一團團的氣。這裏的女人個個懷的都是 $\lceil$ 氣泡孩子」。橋溪莊的人焦慮、恐懼, 卻又找不到解決辦 法。他們將希望寄托在了小孩的名字裏: 雪果、雪山、雪豆、雪強、雪朵, 每個孩子名字裏都有一個「雪」字, 這 些新生命包含著橋溪莊村民對美好生活的期望。他們拜「神女」、舉全村之力請神修廟, 虔誠地請求菩薩顯 靈, 誠懇又愚昧得讓人心酸。李作民一家就是所有橋溪莊村民的縮影, 這裏的老少兩代人歷經了一系列生存 苦難, 最終發現導致自己喪失生活希望的原因在於水泥廠, 即現代化帶來的環境汗染。

水泥廠隱喻現代化帶來的矛盾, 因為它既是希望, 又讓橋溪莊人陷人困境。正如村民李作民經歷的那 樣, 「他們家也在橋溪河邊修了房子, 他們家也要搬下去住了……這些人要往那裏搬是看上了公路, 還有公 路邊的廠子, 搬到那兒住找錢比在只長莊稼和樹的山坡上容易 ${ }^{(5)}$ 。農民為了更好的生活, 放棄了土地, 並未 
Asia-Pacific Journal of Humanities and Social Sciences

深思現代化背後的生態隱暈。就這樣,這些底層民眾卷人了現代化的洪流中,被技術晃花了眼。依靠著省道 與工廠, 橋溪莊慢慢吸引了越來越多李作民這樣的農民, 他們自以為抓住了改變艱苦命運的機會, 不料卻成 了現代化車輪下的犧牲品。空氣裏的浮塵、被汗染的水源, 終於顯示出了現代化的真實面目,橋溪莊的自然 環境與社會環境都遭到了嚴重破壞。

同時, 橋溪莊也直指鄉村的衰落。它不僅作為地域, 呈現著李作民一家的悲慘人生, 更代表著現實生活 中許許多多被現代化機器絞碎的原始鄉村。工業化的強行進軍產生了災難性的生態影響,自然環境遭到嚴 重破壞的村莊既回不到過去, 也看不清未來。在「發展」的幌子下,鄉村王掉了自身的寧靜美麗, 也被工業化 車輪所碾碎, 成了實實在在的現代版鄉村「零余」。橋溪莊正是如此, 它滿目瘡痍, 其中生活的人們也受到現 代文明的擠壓與惡劣環境的影響,城市不接納他們, 世世代代生存的家園又受到了嚴重破壞,讓這些靈魂失 去了歸屬, 只能在絕望中不斷掙紮, 找尋著人生的出路。

\section{二、生殖危機: 畸變與異化的女性形象}

在現代化進程中,女性的生殖與資本的再生產是平行的。機器通過流水線生產著商品, 不斷創造利潤。 而女性如同機器一般懷孕分娩, 傳宗接代, 她們沒有人權, 其情感需求被抹殺, 直接被壓縮為「生育機器」。

橋溪莊的環境破壞與女性從屬地位之間存在著緊密的聯系。現代化的突進一方面破壞著自然環境, 另 一方面讓橋溪莊的男性患上死精疰, 間接導致女性不育。但這些男性在去醫院檢查前, 從未懷疑過自身的生 育能力, 大家口耳相傳的都是 $\lceil$ 橋溪莊裏的女人們懷的都是氣泡孩子」。與此同時, 男性還在不斷地物化、剝 削著女性,女性完全處於被動的位置。橋溪莊的環境破壞與生態失衡使新一代村民陷人雙重困境,生活在這 裏的人不僅與環境矛盾重重,也無法在環境導致的精神絕地中突圍。由於缺失人文關懷, 他們既為汙染所 害, 又困於傳統與現代斷裂之後的仿得之中 ${ }^{\circledR}$ 。

人類學家雪利 - 奧特納 (Sherry B. Ortner) 認為, 女性之所以被某些觀點認為劣於男性, 是因為女性比男

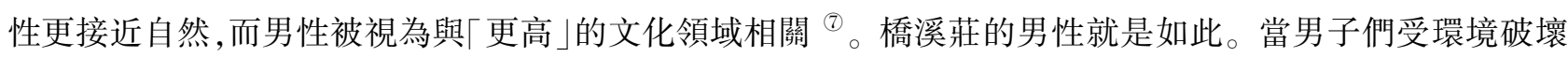
的影響患上了「死精痔」時, 他們沒有醒悟, 只是不停地吃著苦藥, 盼望出現奇跡。身體的缺陷使他們的世界 觀逐漸扭曲, 只能通過剝削女性來撫平自己因失去生育能力帶來的扭曲心理。

首先, 外來女性被橋溪莊男人當作生殖符號。村民陳小路被媳婦蘭香背叛, 從此仇視女性, 幹起了販賣 人口的買賣。英哥和田妮就這樣受到陳小路拐騙,一路被帶到了橋溪莊。英哥和田妮的遭遇是相似的,她們 對陳小路既感激又愛慕, 滿懷愛意打算嫁給陳小路。可是陳小路卻像物品一般將她們賣給了自己的好兄弟。 英哥和田妮被壓縮為生殖符號, 當作可消費的物品進行買賣。她們由從最初的反抗到自暴自棄地認命, 感情 上的漠視竟使她們自己也甘願被物化與符號化,成為男性扭曲心靈自我確認的工具。

其次, 不僅僅是外來女性, 即便是橋溪莊的女人, 也不得不承受命運的戲謔。作品中, 陳大懂與李作民的 妻子沒有名字,她們被稱作 $\lceil$ 陳大懂的女人」與「李作民的女人」, 一生都作為陳大懂與李作民的附屬品存在。 陳大懂的女人以向司機賣炭灰謀生, 她在一次撒炭灰時不小心卷進了大東風的輪子裏, 成了一張血糊糊的 $\lceil$ 肉餅」。李作民的女人之前在水泥廠當粉球籽工人, 吸人肺裏的灰塵讓她整日咳嗽, 不得不在家休養, 整日 遭受著肺病的折磨。丈夫外遇, 兩個孩子瘋頡, 加上身體的病痛, 她失去了活下去的希望。在命運無情的打 擊下,李作民的女人喝農藥結束了自己的生命。

總體上, 橋溪莊的女人靠著男人過活, 將自己的一生都奉獻給丈夫與孩子。她們被世俗的觀念左右著, 沒有明確的身份特征,沒有自我確認的意識, 只能在男性世界中被邊緣化,短暫又潦草地過完了自己的一生。

雪豆是橋溪莊新一代女性中著墨最多的形象。她剛出生時喊出的一句「完了」, 賦予了人物無窮的神秘 
性。這句「完了」更像是末世寓言, 即橋溪莊再也沒有孩子降生。最初, 橋溪莊的人們因雪豆出生就會講話, 把她當作可以療愈不育痽的神女來供奉, 祈求雪豆顯靈。但這並沒有作用, 在香火繚繞中, 人們失望地發現 雪豆只不過是個普通的孩子罷了,那句「完了」說不定是聽錯了。雪豆因過分喜歡貓,被自己的母親叫做「貓 精」。後來, 雪豆的哥哥雪果染上了瘋病, 強奸了雪豆, 她就真的成為一只貓了。貓的眼睛幽幽地看著李作 民他們, 雪豆的眼睛是一對發怒的貓眼, 綠色, 閃著幽光 ${ }^{8}$ 。她把自己蜷成一團, 全身發著抖, 警惕地看著李 作民, 嘴裏發出貓的怒吼聲 ${ }^{(9}$ 。

從 $\lceil$ 神女」到「貓精」, 從神化到動物化, 從神性轉向巫性, 這都是強行賦予雪豆的, 直到貓成了雪豆特有 的隱喻。這些貓是雪豆的情感寄托, 它們在觀音廟中, 日日守著那座可以讓女人幸福的「童子」。沒有人理 解雪豆為什麼喜歡「童子」, 為什麼要嫁給「童子」, 更沒有人關心這些貓, 最終雪豆成為了貓, 貓就是雪豆。 無人理解的雪豆和無人在意的貓不斷交替重叠, 最終融為一體。畸變的村莊與畸變的兄長讓雪豆一步步成 為了貓。她試圖用貓與這個「自然生態環境汗染和社會生態環境汗染的雙重擠壓下 ${ }^{\mathbb{1}}$ 的末世村莊劃清界 限。在雪豆短暫的一生中, 她執著奔向自己心目中的幸福。當理想湮滅, 她逃避、決絕, 最終像那只死去的小 白貓一樣, 魂歸天上。

橋溪莊的生態汗染與人的自我異化有著緊密的聯系。惡劣的生存環境已經註定了他們不幸的命運, 淳 樸的農民成了生態破壞最直接的受難者。這不僅是橋溪莊的悲劇, 更是當代底層民眾生存的「非常態」, 這 個被忽視的社會群體承受了生態失衡下自然的所有怒火。在生態災難的陰影下, 現代化所帶來的利益是短 暫的, 人類最終要自食苦果。王華用悲憫的眼光看著橋溪莊底層民眾的生生死死, 雖無法提出具體的問題解 決方法, 但留給讀者的是可想象、充滿希望的空間。如在小說末尾,橋溪莊的男人們拿著山子給的錢去醫院 看病; 雪朵回家照顧兒子; 田妮無法忍受雪山情感與身體上的雙重暴虐, 選擇了逃跑; 英哥和雪強離開橋溪 莊, 回到有花有草的老家。開放式的結尾, 讓小說及小說中的世界不再一團漆黑。這既隱喻著生態問題的轉 機,也象征著現代化迷思中人的覺醒。

\section{三、精神危機: 離去與死亡}

王華透過《雪豆》, 直抵現代化給人心靈深處帶來的負面影響, 滿懷悲憫又客觀冷靜地描述他們的苦痛, 表現他們的真實生活狀態。當人們的心靈受到現實與精神的雙重擠壓時,離去或死亡成為他們的精神出路。 從在橋溪莊安家落戶到最終的出走與死亡, 這是橋溪莊人生態意識的覺醒史, 也是底層民眾找尋精神家園的 血涙史。

《雪豆》揭示了自然是治療疾病的神聖之地, 也是離去後的應然歸宿。自然給予人類新的生命, 是使心 靈沈靜的溫床。從代表現代化的橋溪莊到自然空間,作品展現了自然的療愈作用。橋溪莊多年來只有「氣 泡孩子」的真相揭露後, 雪強帶著英哥回到了老家。雪強的老家「就是離公路遠了一點, 但那地方有好多樹 啊什麼的」而。多年以來, 橋溪莊人從拜神女、修廟、求菩薩, 到吃藥治病, 但卻始終沒想到, 橋溪莊不是個好 地方 ${ }^{12}$ 。英哥懷上了雪強的孩子, 雖然又是 $\lceil$ 氣泡孩子」, 但他們找到了生活的前路。雪強與英哥從橋溪莊 的出走, 僅僅經歷了生存環境的變化, 即從粉塵隆隆到有花有樹, 但他們的人生也有了奔頭與希望。王華用 獨特的敘事彰顯了自然與荟荟眾生的親緣性, 將自然家園與精神歸宿聯系到一起, 也昭示了回歸自然是最好 的療愈之策,讓人親切的土地才是醫治身心疾病的絕妙去處。

《雪豆》指出了反抗現實的重要意義。身體殘疾、心靈受到巨大創傷的雪果被迫離開了橋溪莊, 但他並 未獲得心靈的救贖, 破滅的愛情使他的人生發生了巨大變化。雪豆的死亡也是如此, 她可以離開橋溪莊, 但 無法接受堅定的愛情理想全部化為虛無。如果李作民的女人與陳大懂的女人是橋溪莊人生態意識覺醒的一 
絲漣渏, 那麼雪豆的死亡就是一聲驚雷, 敲在每一個人的心上。雪豆在樹上結束了自己的生命, 因為樹上離 天近, 可以化成風去天上, 看著這滿目瘡痍的橋溪莊。雪豆短暫的一生以「瘋」為分界點。瘋之前的雪豆對 愛情、幸福懷有不切實際的幻想, 她喜歡的不是山子, 是能讓女人笑的 $\lceil$ 童子」, 山子不過是童子的縮影, 是她 理想愛情的具像化。但經過現實的一系列刺激後,雪豆瘋了,她用一塊幕布把自己和現實生活隔絕開來, 斬 斷和現實世界的聯系, 選擇和同樣癡俊的雪山行走人間。清醒之後的雪豆卻發現自己有了三個月的身孕, 她 對這個世界徹底絕望了。雪豆用自己的生命呐喊:「作民爸, 你跟他們說, 離開橋溪莊。」 ${ }^{13}$ 雪豆用自己的死亡 喚醒橋溪莊的人們, 在這裏既懷不上孩子, 也掙不到出路。作家筆下的人物在現代性的重壓之下不斷畸變, 與自然環境一起分崩離析, 隨之而來的是整個村莊的隱痛與潰爛。雪果出走, 雪豆自殺, 雪山癡俊, 他們被現 實壓迫著, 又用不同的方式反抗現實,最終帶來了希望。

橋溪莊的人們追隨希望而來, 又追隨希望而去。當所有的一切接近崩潰的邊緣, 作者又給了橋溪莊若隱 若現的希望。也許橋溪莊男子的不育疰能治好, 也許人們都會離開橋溪莊, 回到有土地、有莊稼、有花、有草 的老家。故事沒有結局, 但隱含著希望。正如《當代》對作品的評價:「男人死精, 女人氣胎, 鄉村的苦難寓 言, 人間的生死傳說。文壇不缺作家, 不缺才華, 只缺關懷。不缺自我關懷, 只缺眾生關懷。所以, 我們向讀 者推薦貴州省正安縣這位底層作者的長篇習作, 不只為驚人之才, 不只為刻骨之痛, 而是為日漸稀少的人世 悲憫。」王王華在作品中倡導的自然, 既指向山清水秀的自然地域, 同時又是維系著人們心靈情感的紐帶。

整體來看, 王華的生態書寫以《雪豆》為始, 立足現實, 揭露城市化對鄉村與農民的壓倒性姿態。此後的 長篇小說《家園》沿用了《橋溪莊》的寫作手法, 描寫了失去家園的安沙人; 《在天上種玉米》以搬家為線索, 指出土地對農民的重要性; 散文《有個地方叫安沙》《走進夜郎湖》無不體現強烈的生態意識。王華的作品像 是當代農村變化的鏡子,用小人物的離合悲歡,揭露技術發展的另一面。

生態災難是全球在發展中共同面臨的困難, 它是社會、政治、經濟所有問題的共同體現。在構建中國特 色社會主義生態文明的有力話語中, 人們愈發認識到保護自然的重要意義。作為審美意識形態, 文學作品帶 來的精神力量無以倫比。藴含生態意識的作品反映了人們在環境惡化形勢下的不解努力。當現代化的車輪 碾向鄉村, 從環境正義角度觀照底層民眾的生態文學, 更凸顯了其積極意義。生態文學作家以寫實手法描寫 生態災難下的百味人生, 通過文學作品倡導多元的、包容的、可持續的綠色生態理念。《雪豆》正是如此, 它 挖掘了現代化背景下鄉村、底層民眾、女性生存困境的本質, 倡導生態中心主義, 以求建立人與人、人與自然 的和諧關系,想像性地建構理想的、且在生態意識影響下即將成為現實的精神家園。

\section{註釋}

(1) 文静: 《從〈椅溪莊〉看王華的生態文學創作》,《凯襄學院學報》2012 年第 4 期。

(2) 謝廷秋:《海雀: 那片令人心動的樹林——生態視域下的王華作品解讀》,《䒧術評鍳》2020 年第 23 期。

(3)(4)(5)(9)(11)(1213 王華著:《雪豆》, 中國電影出版社 2007 年版, 頁 6、2、160、165、166、144、194、228。

(6)10 鄭晶燕: 《生存在世界邊緣的人: 解讀〈橋溪莊〉》,《理論與當代》2006 年第 12 期。

(7) Vakoch, Douglas A. (2014). Feminist ecocriticism: environment, women, and literature. New York: Lexington Books. (14) 王華:《橋溪莊》, 《當代》2005 年第 1 期。

(Editor: Bonnie Wang) 